\title{
Investigation of water sources as reservoirs of Vibrio cholerae in Bepanda, Douala and determination of physico-chemical factors maintaining its endemicity
}

Authors:

Akoachere J.-F.K. Tatah ${ }^{1,2}$ Kwedjeu M.C. Pulcherie ${ }^{1}$ Ndip L. Mande ${ }^{1,2}$

Njom H. Akum²

\section{Affiliations:}

${ }^{1}$ Department of Biochemistry and Microbiology, University

of Buea, Cameroon

${ }^{2}$ Laboratory for Emerging

Infectious Diseases,

University of Buea,

Cameroon

Correspondence to:

Akoachere Tatah

Email:

jakoachere@yahoo.com

How to cite this poster: Tatah, A.J.-F.K., Pulcherie, K.M.C., Mande, N.L. \& Akum, N.H., 2012, 'Investigation of water sources as reservoirs of Vibrio cholerae in Bepanda, Douala and determination of physico-chemical factors maintaining its endemicity', Onderstepoort Journal of Veterinary Research 79(2), Art. \#484, 1 page. http:// dx.doi.org/10.4102/ojvr. v79i2.484

Note:

Proceedings of the

Conference of the Southern African Centre for Infectious Disease Surveillance 'One Health' held at the National Institute for Communicable Diseases, Johannesburg, July 2011.
Cholera remains a significant cause of mortality in developing countries. Outbreaks of the disease are associated with poverty, lack of potable water and poor sanitation. The survival and persistence of Vibrio cholerae in water has been shown to depend on physico-chemical factors. We studied water sources in Bepanda, an overcrowded neighbourhood in Douala, Cameroon, with limited access to portable water and very poor sanitary conditions as reservoirs of $V$. cholerae.

We analysed 318 samples from various sources (well, tap, stream) from February to July 2009 using standard microbiological techniques and characterised isolates serologically using the polyvalent $\mathrm{O} 1 / \mathrm{O} 139$ antisera. Susceptibility to antibiotics previously used for cholera treatment in Douala was studied using the disk diffusion method. Physico-chemical factors (temperature, $\mathrm{pH}$ and salinity) that could maintain the endemicity of the organism were analysed using standard methods. Eighty-seven (27.4\%) samples were contaminated, with high isolation rates being obtained from streams (52.4\%) and wells (29.8\%). The number of isolates was significantly higher $(P<0.05)$ in the rainy season $(35.5 \%)$. We detected $23(24 \%)$ O1 serogroup isolates in streams and wells, whilst $64(66.6 \%)$ were non-O1/non-O139. Temperature and salinity correlated positively with the occurrence of the organisms. All isolates were susceptible to fluoroquinolones but high resistance rates to trimethoprim or sulfamethozaxole and tetracycline were observed.

Vibrio cholerae is endemic in Bepanda with $\mathrm{O} 1$ and non-O1/non-O139 serogroups co-existing in the streams and wells hence the possibility of future outbreaks of cholera if sanitation and drinking water quality are not improved. Temperature and salinity are amongst the factors maintaining the endemicity of the organism.
(C) 2012. The Authors. Licensee: AOSIS OpenJournals. This work is licensed under the Creative Commons Attribution License. 